\title{
COVID-19, long flights, and deep vein thrombosis: What we know so far
}

\author{
Zbigniew Krasiński®, Andre Chou®, Hubert Stępak® \\ Department of Vascular and Endovascular Surgery, Angiology, and Phlebology, \\ Poznan University of Medical Sciences, Poznan, Poland
}

\begin{abstract}
The severe acute respiratory syndrome coronavirus 2 (SARS-CoV-2) (coronavirus disease 2019 [COVID-19]) pandemic has presently stunted the growth of the airline industry. Despite the setbacks, pre-COVID-19 passenger numbers are forecasted to return by as early as 2024. As the industry recovers, the number of long-distance flights will surely continue to increase like it did before the pandemic. The incidence of venous thromboembolism (VTE) following air travel is also likely to increase. Although not common, the unique environment of air travel exposes individuals with particular health conditions to an elevated risk of acquiring VTEs. Numerous factors increasing the risk of developing VTE related to air travel have been identified, including inherited and acquired flight-related aspects. Non-pharmacological approaches to reduce air travel-related VTEs involve simple foot movements, compression socks and stockings, intermittent pneumatic compression devices, a novel modified airline seat, and foot exercisers. Pharmacological methods include heparins and direct oral anticoagulants. More than 30 reliable articles were evaluated to present the current knowledge regarding air travel-related VTEs, their risk factors, and prophylactic methods. Issues in research methodologies found in the literature were identified and discussed. Further research involving international collaboration projects is recommended. The authors' perspectives regarding long flights in previously infected COVID-19 individuals are also included. (Cardiol J 2021; 28, 6: 941-953)
\end{abstract}

Key words: deep vein thrombosis, economy class syndrome, pulmonary embolism, travel-related illness, venous thromboembolism, COVID-19

\section{Introduction}

Despite the effects of the ongoing severe acute respiratory syndrome coronavirus 2 (SARS-CoV-2) (coronavirus disease 2019 [COVID-19]) pandemic, the airline industry is projected to recover by 2024. New estimates from the International Air Transport Association predict passenger numbers to double by the year 2039 , compared to pre-COVID-19 years [1]. As new technologies allow for more affordable travel over long distances, a yearly passenger growth rate of $7 \%$ since 2015 had been recorded until the onset of COVID-19 [2, 3].
The long periods of immobility and cramped conditions seen in most air travelers is reflected in the term "economy class syndrome" [4-6]. Therefore, the growing number of long-range routes and passenger numbers is likely to increase the incidence of pulmonary embolism caused by deep vein thrombosis (DVT) [7]. It is estimated that in other automotive forms of transport, the risk for venous thromboembolism (VTE) amounts to between $0.5 \%$ and $10 \%$ after travelling longer than 12 and 24 hours, respectively $[7,8]$. The findings of the article are summarized in the Central illustration.

Address for correspondence: Dr. Hubert Stępak, MD, PhD, Department of Vascular and Endovascular Surgery, Angiology, and Phlebology, Poznan University of Medical Sciences, ul. Długa 1/2, 61-848 Poznań, Poland, tel: +48 618549141 , e-mail: hstepak@gmail.com

Received: 26.01.2021 Accepted: 5.07.2021 Early publication date: 2.08.2021

This article is available in open access under Creative Common Attribution-Non-Commercial-No Derivatives 4.0 International (CC BY-NC-ND 4.0) license, allowing to download articles and share them with others as long as they credit the authors and the publisher, but without permission to change them in any way or use them commercially. 


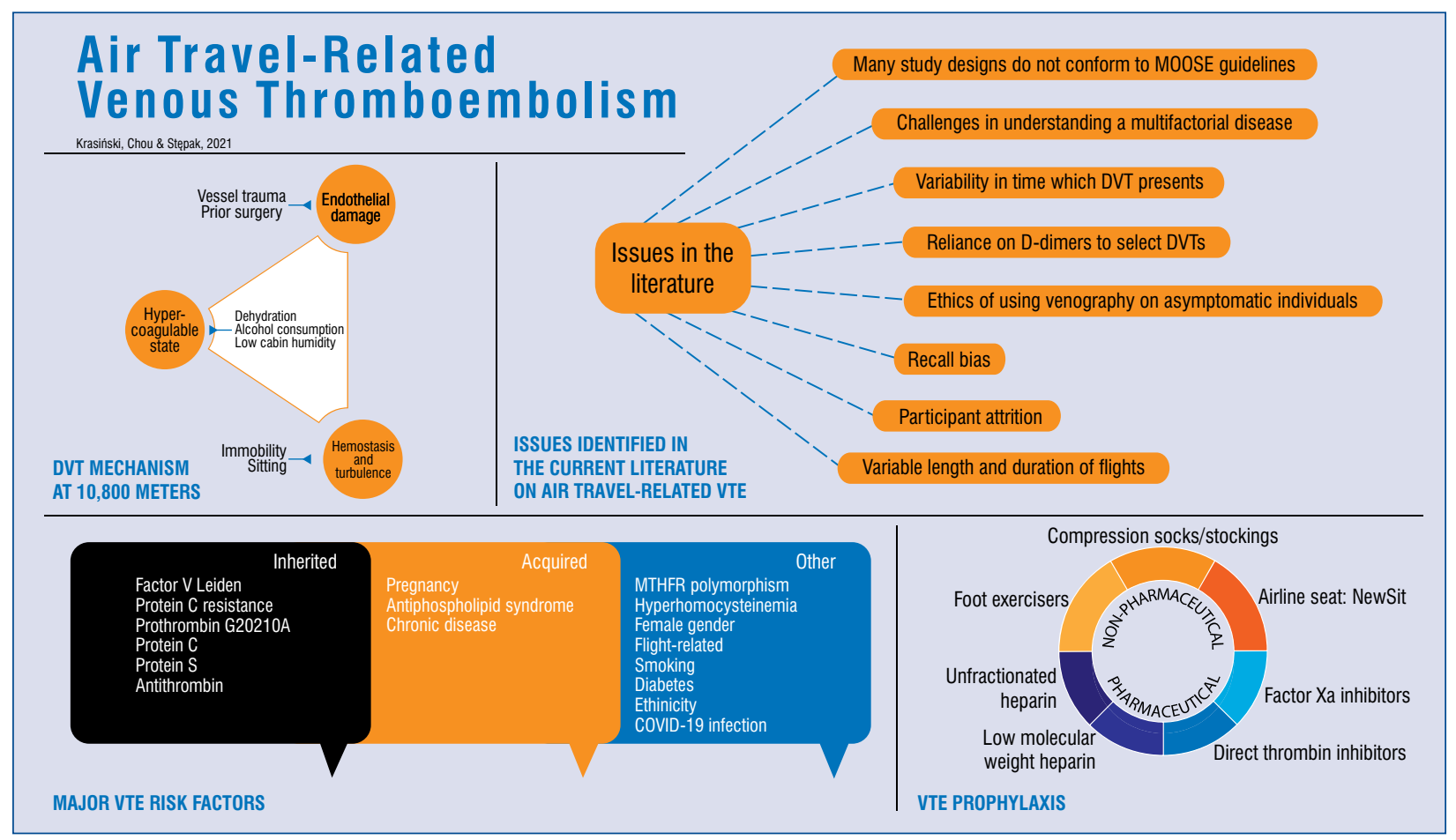

Central Illustration. Graphical summary of the article's findings on air travel-related venous thromboembolism (VTE); DVT — deep vein thrombosis.

\section{Review methods}

Reviews of medical articles relating to air travel-related VTE, risk factors, and prophylaxis were conducted. Medical journals in the English language were selected for review using PubMed and Google Scholar. The keywords used included "economy class syndrome", "pulmonary embolism", "deep vein thrombosis", "venous thromboembolism", "venous thromboembolism prophylaxis", and "air travel-related illness" either as standalone searches or in combination. Additional publications not recovered in the preliminary searches were reviewed and added if deemed suitable to the topic. Finally, 30 articles were selected for review. Additional literature not previously captured was added to supplement the review based on its relevance to the scope of interest.

\section{Mechanism}

Virchow's triad details the conditions contributing to venous thrombosis, i.e. endothelial injury, venous hemodynamic changes (stasis and turbulence), and hypercoagulability $[9,10]$. Damage to the endothelium causes platelets to bind to the injury site, forming a hemostatic plug, which may become the nidus of thrombosis [9]. Two common causes of vascular injury include surgery and major trauma. Hypobaric hypoxia, low humidity, and immobility are commonly seen in air travel $[9,11]$.

\section{Hypobaric hypoxia and low humidity}

At $10,800 \mathrm{~m}$, airplanes are pressurized to create a livable environment, which equates to an altitude of between 1524 and $2134 \mathrm{~m}$, and a cabin pressure of $75.8 \mathrm{kPa}$ (101 kPa AMSL) [11]. In such conditions, the oxygen saturation in healthy individuals can decrease to $90-93 \%$, whereas in the elderly and passengers suffering from cardiac or pulmonary disorders, it may be as low as $80 \%$ [9]. Although coagulation in hypobaric and normobaric hypoxia conditions have been the subject of a number of studies, there remains a lack of consensus regarding thrombin formation in the aforementioned conditions [12].

The humidity level in an aircraft is approximately $10 \%$ (compared to sea level 30-40\%) [13]. This effect is exacerbated by decreased fluid intake, which may result in dehydration [9]. In a simulated long flight study, no evidence concerning dehydration was found, although fluid retention corresponding to an approximate increase of $1 \mathrm{~kg}$ in body weight was observed [14]. An increase in urinary and plasmatic osmolarity associated with a low humidity combined 
with the diuretic effect of beverages, such as coffee, tea, or alcohol contribute to hemoconcentration promoting VTE formation [9].

\section{Immobility}

The endothelium can be deprived of its non-thrombogenic state without direct injury [10]. Immobility causes stasis, which forms a chemotactic gradient across the endothelium, triggering major leukocyte migration. Furthermore, leukocyte trapping can occur between the basement membrane and the endothelium, resulting in endothelial cell separation and desquamation, which further leads to the exposure of subendothelial layers and thrombus formation [10]. Thus, the immobility of passengers in long-distance travel is referred to as "economy class syndrome" [5]. As experienced by passengers mainly in economy class, those in window seats would have a twofold increase in risk for a VTE compared to those seated by the aisle [15].

\section{Endurance athletes}

Individuals in excellent physical condition can also be at risk of a travel-related VTE. In particular, endurance athletes and long-distance runners experience repeated microtrauma, which may induce endothelial injury. Additionally, dehydration can lead to hemoconcentration while immobility during travel to and from events contribute to VTE formation [16]. In Paget-Schrötter syndrome, heavy upper extremity activities can activate coagulation in the axillo-subclavian vein [17]. Rare iliofemoral DVT known as May-Thurner syndrome has been described in a runner [18]. Indeed, a report of a triathlete diagnosed with DVT upon completion of a half-ironman triathlon indicates that DVT risk factors, such as microtrauma, immobility, and dehydration may also be present in this population [16].

\section{Risk factors}

The most common risk factors for flight-related VTEs are thrombophilic abnormalities and the occurrence of previous DVT [11]. Others include obesity (body mass index [BMI] $>30 \mathrm{~kg} / \mathrm{m}^{2}$ ), age ( $>40$ years old), tall and short stature ( $>1.90 \mathrm{~m}$ or $<1.60 \mathrm{~m}$ ), chronic disease, oestrogen administration, female gender, pregnancy, and immobility [19-21]. A new risk factor for VTE is undoubtedly related to COVID-19 infection [22]. At present, data are scarce regarding the implications for long-haul flights in individuals who are or have previously been infected with COVID-19, although the coagulopathy observed in the disease may increase the risk of VTE [23]. Because this is a developing topic within the literature, the authors offer some perspectives in the section "COVID-19: Authors' perspectives".

In general, although most sufferers of air travel-related VTEs are older, young and physically fit individuals can also be at risk [16, 24]. In a study, travelers' absolute VTE risk was evaluated, and the identified risks were as follows: $1 / 109$ for pregnant travelers, $1 / 140$ for travelers in a plaster cast, $1 / 141$ for travelers with malignancies, $1 / 164$ for travelers following a recent surgery, $1 / 259$ for travelers on contraceptives, and 1/405 for female travelers on hormone replacement therapy [25].

\section{Inherited factors}

Inherited thrombophilias predispose individuals to hypercoagulable states [26]. The prothrombin gene constitutes the most frequent cause of hereditary hypercoagulable conditions, comprising $50-60 \%$ of VTE cases, whereas factor V Leiden mutations with antithrombin, and protein $\mathrm{C}$ and $\mathrm{S}$ represent the remainder [26]. A study showed that in $72 \%$ of travel-related VTE cases thrombophilic irregularities were present [11].

\section{Factor V Leiden and activated protein C resistance}

There is an elevated VTE risk in individuals with factor V Leiden (FVL) (in which insensitivity to activated protein C [APC] is observed) [9]. Moreover, APC resistance was detected in $47 \%$ of individuals with travel-related VTE [11]. Thus, even without FVL, APC resistance constitutes a risk factor for VTE, and it was observed in $15 \%$ of patients with travel-related VTE [11].

\section{Prothrombin G20210A}

Mutations to prothrombin constitute the second most frequently inherited thrombophilia after FVL [11]. Combined mutations of FVL and prothrombin gene $20210 \mathrm{~A}$ are linked with a greater risk of VTE [27]. In a travel-related VTE study, a synergistic increase in the risk for DVT was found in FVL individuals, although the VTE risk for prothrombin mutations was less pronounced [28].

\section{Protein $\mathrm{C}$ and protein $\mathrm{S}$}

Protein $\mathrm{C}$ is a vitamin $\mathrm{K}$-dependent anticoagulant protein, circulating as a zymogen. Anticoagulant effects are exerted following the activation to APC which, in turn, inactivates factors Va and VIIIa, further activating factor $\mathrm{X}$ for thrombin formation 
[27]. Protein C deficiency was identified in $4.8 \%$ of individuals with travel-related VTE [11]. Protein S is a cofactor for APC and regulates clot formation [29]. Deficiencies of protein S were found in $7 \%$ of patients experiencing travel-related VTE. Protein C and protein $\mathrm{S}$ levels are decreased by vitamin $\mathrm{K}$ deficiency, warfarin, and liver failure [30].

\section{Antithrombin}

Antithrombin is an inhibitor of thrombin, factors IXa and Xa, and other serine proteases. Deficiency of antithrombin is either inherited or acquired. Inherited deficiencies result from mutations, whereas acquired deficiencies are primarily caused by impaired production of viable antithrombin, increased utilization, or protein losses [31]. Antithrombin deficiency may result in an elevated thrombotic risk and heparin insensitivity. In an air travel-related VTE study, $3(<2 \%)$ subjects with VTE suffered from antithrombin deficiencies [32].

\section{Other}

According to the literature, non-O blood groups have higher plasma levels of von Willebrand factor and factor VIII, which may lead to an elevated risk for thrombosis [13]. Fibrinogen gene mutation $\mathrm{C} 10034 \mathrm{~T}$ is known to produce variant fibrinogen linked with increased venous thrombosis [13]. Furthermore, lupus anticoagulant, anti- $\beta 2$-glycoprotein I, and antiprothrombin antibodies participate in prolonged coagulation in vitro [33].

\section{Acquired factors \\ Pregnancy}

Many adaptive changes occur in the hemostatic system as the body prepares for placental expulsion and vascular disruption [34]. The body enters a state of hypercoagulability and hypofibrinolysis in order to prevent excessive bleeding [34]. Although VTE risk during pregnancy is low, the postpartum risk is 5 times higher than during pregnancy [35]. However, the risk for VTE is estimated to be between $0.03 \%$ and $0.1 \%$ when the two factors, i.e. air travel and pregnancy, are combined [36]. Indeed, pregnant women on 4- to 5 -hour flights have a VTE risk 5 to 10 times greater than non-pregnant women, and the risk increases to 4 and 8 times in flights longer than 8 and 12 hours, respectively [9].

Trophoblastic injury triggered by flight-related hypoxic conditions leading to premature birth and intrauterine death were reported [37]. Therefore, airlines have introduced restrictions on pregnant women, allowing travel only up to the $36^{\text {th }}$ week of pregnancy [13]. Following findings presented by the Royal College of Obstetricians and Gynecologists, it is accepted that pregnancy is at least a moderate risk factor and requires further investigation [38]. Pharmacological prevention should also be evaluated in this group of travelers [24].

\section{Antiphospholipid syndrome}

Antiphospholipid syndrome is an autoimmune disorder in which antibodies against proteins are bound to anionic phospholipids on plasma membranes [26]. Secondary antiphospholipid syndrome was observed in rheumatic diseases such as systemic lupus erythematosus or as a standalone disease [26]. Although VTE occurrences were reported in nearly all locales of the vascular tree in antiphospholipid syndrome patients, the most frequently reported are lower extremity DVTs and pulmonary embolisms [39].

\section{Chronic disease}

Numerous cases of VTE are associated with chronic disease [19]. Chronic lung or cardiovascular diseases can be exacerbated by the hypoxic conditions in air travel (i.e. induction of the coagulation system during a flight) [40]. Arthritis and inflammatory bowel disease were also identified as potential risk factors together with neoplastic diseases and chronic kidney disease [9, 21]. Indeed, the death of New Zealand international rugby icon Jonah Lomu, who had been diagnosed with nephrotic syndrome, was suspected to be caused by a VTE shortly after a long-distance flight from the United Kingdom to New Zealand [41].

Obesity $\left(\mathrm{BMI}>30 \mathrm{~kg} / \mathrm{m}^{2}\right)$ is a widely reported risk factor in several VTE studies [9, 21]. In fact, a relative risk of 2.4 for DVT was determined when comparing non-obese and obese women [42].

\section{Other factors}

MTHFR polymorphism

and hyperhomocysteinemia

5,10 -methylenetetrahydrofolate is reduced to 5-methyltetrahydrofolate using methylene tetrahydrofolate reductase (MTHFR). Methyl tetrahydrofolate is required in the re-methylation of homocysteine to methionine, a process that requires folate and vitamin $B_{12}$ [43].

Indeed, MTHFR polymorphisms were linked to an increased VTE risk [27]. MTHFR compound mutations entail a greater risk for VTE compared to heterozygous, homozygous C677T, or A1298C variants which constitute an intermediate risk [44]. It has been demonstrated that geographic 
and ethnic variations exist in the population. Homozygosity for C677T in North America is most prevalent in Hispanics (21-25\%), followed by Whites (10-14\%), and Blacks (1-2\%, particularly in the USA and Brazil), whereas homozygosity for A1298C is found more in Whites (7-12\%) followed by Hispanics (4-5\%) and Asians (1-4\%) [45]. In contrast, heterozygosity was not considered a risk factor for VTE [11].

Hyperhomocysteinemia is another important risk factor for initial and recurring VTE, especially when fasting levels exceed $20 \mu \mathrm{mol} / \mathrm{L}$ [46]. The most commonly known genetic cause of hyperhomocysteinemia is MTHFR gene polymorphism [27]. Acquired hyperhomocysteinemia can stem from chronic renal failure, or it can be induced by drugs such as cyclosporine and methotrexate [11]. Additionally, folate, vitamin $\mathrm{B}_{6}$, and vitamin $\mathrm{B}_{12}$ deficiencies due to a low dietary intake can also result in mild to moderate hyperhomocysteinemia [47].

\section{Female gender}

Female gender is an independent risk factor for flight-related VTE. According to Lapostolle et al. [6], 75\% (42 of 56) of confirmed VTE patients were female. Additionally, a large cohort study found the VTE risk for females is 3 times higher than for men [20]. Moreover, an increased VTE risk is also observed in menopausal women receiving hormone replacement therapy; in individuals undergoing estrogen therapy, the risk of VTE is nearly 20 times higher [21, 48]. The use of the oral contraceptive pill (OCP) in healthy women increases VTE risk fourfold [49]. According to the Centers for Disease Control and Prevention, $12.6 \%$ of women between 15 and 49 years of age take the OCP in the USA [50]. Worldwide, 65 million women take the OCP, which amounts to $6 \%$ of all women of reproductive age [11]. Indeed, the increased risk of VTE events when using OCP is well established in the literature [49].

\section{Flight-related}

Long-distance flights are defined as lasting 7 to 15 hours or more $[51,52]$. According to the literature, the risk of DVT for such flights equals $3-12 \%$ and is 3 times higher in comparison to shorter travels [53].

Arya et al. [51] found that long-haul flights $(>8 \mathrm{~h}$ ) were associated with DVT only if one additional risk factor was present.

Window and central seating locations are significant. Belcaro et al. [54] observed that 18 of 19 thromboses were formed in subjects sitting by the window or in central seats. In their subsequent study, all 22 DVT cases (of 422 subjects) were reported in passengers seated by the window or in central seats. As for so-called "economy class syndrome", the risk was the same for business and economy class travelers $[48,55]$. Therefore, the term "traveler's thrombosis" has been suggested as a more appropriate term [56].

As discussed previously, alcohol contributes to the diuretic effect, thereby increasing the risk of VTE. Interestingly, $66 \%$ more alcohol is consumed in business class than in economy class [55].

\section{Other}

A hypercoagulable state in type I and II diabetes has been established. Chronic hyperglycemia can lead to endothelial dysfunction and is crucial for the progression of vascular complications in diabetic patients [57]. In several studies diabetes was frequently used as an indicator or as an exclusion criterion of high-risk VTE in long-haul flights [58-60].

Smoking is reportedly a risk factor for travel-related VTE because it causes hypoxia and increases blood viscosity [13, 57, 61]. In women taking OCPs, smoking acts synergistically in increasing VTE risk [62]. Interestingly, while one study demonstrated that smoking was unrelated to D-dimer development and found little evidence of its association with VTE, while another study classified smoking as a low risk for VTE [55, 63]. Nevertheless, cessation of smoking to decrease VTE risk was recommended in other studies [6, 61].

Recent surgery represents a well-described risk for VTE [9, 21, 64]. Surgery risk was divided into low (minor surgery within 3 days of a flight) and high risk (major surgery within 6 weeks of a flight) [13].

An individual with a history of previous DVT or pulmonary embolism is at high risk of developing VTE [6, 27].

The impact of race and ethnicity on VTE risk has been scarcely investigated. According to White and Kenan, African Americans had a notably higher rate of VTE, particularly following events which include surgery, illness, and trauma [65]. Pacific Islanders and Asians had between 3 and 5 times lower risk for cancer-associated VTE, and idiopathic first-time symptomatic and secondary VTE [65]. Using Caucasians as the reference ethnic group for any first-time VTE risk, the less vulnerable groups were Hispanics (50\%) and Asians/ /Pacific Islanders (70\%), whereas African Americans were 35\% more vulnerable to VTE [66]. Al- 
though genetic factors are more present in some ethnic groups, the data regarding air travel-related VTEs remain insufficient.

\section{Prevention: Non-pharmacological}

General advice on inflight exercises for travelers is available from airline websites and on-board entertainment systems and includes stretching, foot exercises, standing up, removing bags from under the seat for more leg space, and avoiding restrictive clothing [59, 67]. Foot exercises increase the mean peak velocity in the popliteal vein and can be activated by frequent plantarflexion and dorsiflexion [68]. However, data concerning the compliance and efficacy of such exercises are scarce.

For higher-risk individuals, compression socks/stockings, intermittent pneumatic compression devices, and active foot movements have been shown to be effective [21]. The mechanism is attributed to the high flow pulsatility induced by the vessel collapse due to distal compression (by muscle contraction) allowing deep veins to drain more readily, thereby reducing venous stasis [69]. External mechanical compression does not affect coagulation; hence, the risk of increased bleeding with this method is minimal.

\section{Compression stockings}

Passengers using compression stockings have reduced incidences of DVT and lower extremity edema [54]. In LONFLIT 2, the frequency of DVT among high-risk individuals in long-haul routes was reduced 18.5 times when wearing stockings [54]. The LONFLIT 4 Concorde Edema-SSL study evaluated Scholl (UK) Flight Socks (below knee, 14-17 mmHg compression at the ankles) and found a distal DVT in less than $1 \%$ of the study group compared to $6 \%$ in the controls $[54,70]$. In the LONFLIT 4 Concorde ECO-TRAS study, similar results were found regarding Sigvaris Traveno (Ganzoni, Switzerland) elastic stockings (below knee, $12-18 \mathrm{mmHg}$ compression the ankles) [71]. Thigh-length socks were found to have equivalent effectiveness compared with knee-length although the latter has better compliance and a lower cost [72]. Similar efficacy was also reported in graded compression stockings [73].

\section{Intermittent pneumatic compression devices}

Intermittent pneumatic compression devices, calf muscle pump-facilitating devices, and simple foot movements were compared [74]. Calf muscle pump facilitating devices did not present a higher efficacy than simple foot movements, whereas the use of intermittent pneumatic compression devices was found to be justifiable for sleeping, or immobile patients [74]. The use of intermittent pneumatic compression devices on flights is restricted due to the external power source, size, and weight requirements; thus, compression stockings are preferred [75].

\section{Modified airline seat}

A modified standard airline seat (NewSit) was proposed, which elevates the feet, assisting leg mobility and allowing intermittent calf compression [76]. Improvement in venous emptying was observed in 23 out of 25 subjects whilst sitting for 5 hours, in comparison to a conventional airline seat [76]. Currently, this is the only published paper concerning this technology.

\section{Foot exercisers}

Physical foot exercisers, such as the Airogym Exerciser (Airogym Ltd., UK) and travel footrest hammocks (various brands), are less common, although they do promote blood flow through deep veins [77].

\section{Prevention: Pharmacological}

Pharmacological methods aim to decrease coagulation and clot formation. Common drugs include low-molecular-weight heparin (LMWH), unfractionated heparin (UFH), factor Xa inhibitors, direct thrombin inhibitors, and acetylsalicylic acid (ASA) [24, 48]. Such methods to decrease or prevent DVT can be employed when compression, or other physical methods are contraindicated, as in the case of severe arterial claudication, drug allergies, or high hemorrhage risk [78]. The main advantages of the pharmacological measures are the increased compliance when compared to non-pharmacological methods [78]. Crucially, for individuals undergoing long-term anticoagulant therapy with a proven prevention of recurring VTE (following an unprovoked first event), the same effect cannot be presumed when administering these medications shortly before travel [79].

\section{Heparins}

Conventional evidence-based guidelines for the treatment and prevention of DVT are with heparins [79]. Data regarding UFH use for pre-flight DVT prophylaxis is scarce because it is normally used instead in the treatment of acute VTE in controlled settings due to the intensive activated partial thromboplastin time demands [24, 80]. 
Low-molecular-weight heparin has replaced UFH as the drug of choice for VTE prophylaxis [64]. The efficacy of LMWH is well documented and recommended for high-risk individuals on long-distance flights [81]. LMWH has certain advantages over heparin, such as a lower risk of heparin-induced thrombocytopenia at $0.2 \%$ vs. $2.6 \%$, respectively, and better pharmacokinetic profile [82]. In a study, a LMWH group who were administered $1 \mathrm{mg} / \mathrm{kg}$ of enoxaparin between 2 and 4 hours before a long-distance flight reported $0.61 \%$ of thrombotic events in the extremities compared to $4.8 \%$ in the control group and $2.9 \%$ in the ASA group ( $\mathrm{p}=0.002$ when compared to the two other groups). Additionally, recommendations for a single $40 \mathrm{mg}$ dose of enoxaparin or $5000 \mathrm{IU}$ of dalteparin subcutaneously prior to departure have also been made [24]. LMWH's route of administration is not the most convenient, which decreases its compliance [83].

\section{Direct oral anticoagulants: Factor Xa and direct thrombin inhibitors}

Due to minimal food and drug interactions, direct oral anticoagulants are a safer alternative than the previous methods [61]. Furthermore, there is no evidence suggesting direct oral anticoagulants cannot be used as prophylaxis for travelrelated VTE. However, as primary prophylaxis, LMWH is still preferred due to the novelty and thereby lack of data regarding direct oral anticoagulants [83].

Factor Xa transforms prothrombin to thrombin and thus is essential for coagulation. rivaroxaban is a direct inhibitor of factor Xa [83]. Oral administration of $10 \mathrm{mg}$ was recommended for the prevention of VTE [84]. Another direct factor Xa inhibitor is apixaban, but there are no data on its safety or efficacy for long-haul flight VTE prophylaxis [85].

An indirect factor $\mathrm{Xa}$ inhibitor is fondaparinux [86]. In comparison to LMWH, fondaparinux may increase the risk for fatal hemorrhage; on the other hand, when compared to UFH, it increases all-cause mortality, simultaneously reducing VTE events [87]. An informal cost analysis of the drug indicated fondaparinux to be more expensive than LMWH [80]. A recommendation for pre-flight VTE prevention is $2.5 \mathrm{mg}$ subcutaneously [24]. Contraindications for factor Xa inhibitors are renal insufficiency (creatinine clearance $<30 \mathrm{~mL} /$ $/ \mathrm{min}$ ) and hemodialysis [24].

Dabigatran etexilate is a thrombin inhibitor with a similar efficacy to enoxaparin and a comparable safety profile to LMWH [24]. It has predictable pharmacokinetics, a rapid onset of action, and minimal drug and food interactions. A recommended prophylactic dosage is reported as $220 \mathrm{mg}$ once per day [88].

\section{Acetylsalicylic acid}

Acetylsalicylic acid inhibits platelet activation by the inactivation of cyclooxygenase. ASA used in combination with stockings has proven to be beneficial, although very few studies support ASA use for VTE prophylaxis [56, 89]. Subjects of the LONFLIT 3 study were administered $400 \mathrm{mg}$ once daily for 3 days, beginning the first dose 12 hours prior to the flight. The results indicated a small decrease of $3.6 \%$ in subjects with DVT compared with $4.8 \%$ in the control group; however, this result was not statistically significant [81]. The efficacy of ASA as a standalone drug in VTE prevention is doubtful; hence, the American College of Chest Physicians have advised against its use for thromboprophylaxis [56].

\section{Discussion}

It is generally accepted that air travel is related to VTE $[53,90,91]$. However, the issue of heterogeneity in the literature remains problematic, although explicable. Despite various definitions of a "long-distance" flight, the research performed has been extensive in methodology, variables, sampled populations, and locations, offering various opinions on the inclusion or exclusion criteria [51, 92]. Major papers and findings are summarized in Table 1.

The conundrum of air travel-related VTE is that it constitutes a multifactorial disease [9]. Distance or length traveled, individual variables, air travel conditions, passenger behaviors during travel, and recent events prior to travel such as trauma and surgery, all interact to produce different outcomes [56]. Thus, it is very challenging to identify the exact factors resulting in travel-related VTE.

The great variety of study designs in the literature is encouraging [56]. However, the variability in the study protocols has in some cases impeded subsequent meta-analyses [53]. Numerous studies do not meet the criteria for inclusion to meta-analyses (such as the MOOSE guidelines) and thus are unable to contribute to the existing literature [53, 93]. Chandra et al. [53] reported issues with study design, in particular regarding the use of control participants. The idea that control participants should be similar to the case patients is 
Table 1. Major papers on air travel-related venous thromboembolism (VTE).

\begin{tabular}{|c|c|c|c|}
\hline Authors & Year & Study type & Findings \\
\hline Ferrari et al. [90] & 1999 & Case control & Travel is a risk factor for VTE \\
\hline Kraaijenhagen et al. [91] & 2000 & Case control & $\begin{array}{l}\text { No association between VTE } \\
\text { and long-distance travel }\end{array}$ \\
\hline Arya et al. [51] & 2002 & Case control & $\begin{array}{l}\text { DVT risk only increased in long-haul travelers } \\
\text { if additional risk factors are present } \\
\text { - prophylaxis recommended }\end{array}$ \\
\hline Martinelli et al. [32] & 2003 & Case control & $\begin{array}{l}\text { Air travel doubles the risk for VTE, } \\
\text { and the presence of thrombophilia or oral } \\
\text { contraceptives increases the risk } \\
16 \text { and } 14 \text { times, respectively }\end{array}$ \\
\hline Schwarz et al. [102] & 2002 & Cohort pilot & $\begin{array}{l}\text { Passengers with isolated calf vein thrombosis } \\
\text { reported other risk factors for thrombosis }\end{array}$ \\
\hline Schwarz et al. [48] & 2003 & Cohort & $\begin{array}{l}\text { Flights longer than } 8 \text { hours double the risk for } \\
\text { isolated calf muscle venous thrombosis }\end{array}$ \\
\hline Lapostolle et al. [6] & 2001 & Retrospective & $\begin{array}{l}\text { A greater distance traveled is a significant } \\
\text { contributor to air travel-related PE }\end{array}$ \\
\hline Pérez-Rodríguez et al. [52] & 2003 & Retrospective & $\begin{array}{l}\text { Air travel is a risk factor for VTE, and its } \\
\text { incidence increases with the journey duration }\end{array}$ \\
\hline Scurr et al. [7] & 2001 & Randomized trial & $\begin{array}{l}\text { Asymptomatic DVT in up to } 10 \% \text { of } \\
\text { long-haul air travelers. Wearing compression } \\
\text { stockings associated with a reduction } \\
\text { in asymptomatic DVT }\end{array}$ \\
\hline $\begin{array}{l}\text { Belcaro et al., } \\
\text { LONFLIT } 1 \text { [59] }\end{array}$ & 2001 & Cross-sectional & $\begin{array}{c}\text { Flight related DVTs were found in individuals } \\
\text { who presented a high risk or sitting in the } \\
\text { window and central seats }\end{array}$ \\
\hline $\begin{array}{l}\text { Belcaro et al., } \\
\text { LONFLIT } 2 \text { [59] }\end{array}$ & 2001 & Randomized trial & $\begin{array}{c}\text { Compression therapy (stockings) decreased } \\
\text { DVT incidence in long-haul flights }\end{array}$ \\
\hline $\begin{array}{l}\text { Cesarone et al., } \\
\text { LONFLIT } 3[81]\end{array}$ & 2002 & Randomized trial & $\begin{array}{l}\text { LMWH use almost eradicated } \\
\text { thrombotic events }\end{array}$ \\
\hline $\begin{array}{l}\text { Belcaro et al., } \\
\text { LONFLIT } 4 \\
\text { Concorde Edema-SSL [103] }\end{array}$ & 2002 & Randomized trial & $\begin{array}{l}\text { Scholl Flight Socks are effective in controlling } \\
\text { edema and reducing DVT incidence in low } \\
\text { to medium risk subjects on long-haul flights }\end{array}$ \\
\hline $\begin{array}{l}\text { Cesarone et al., } \\
\text { LONFLIT } 4 \\
\text { ECO-TRAS [71] }\end{array}$ & 2003 & Randomized trial & $\begin{array}{l}\text { Sigvaris Traveno Stockings are effective in } \\
\text { controlling edema in long-haul flights }\end{array}$ \\
\hline $\begin{array}{l}\text { Cesarone et al., } \\
\text { LONFLIT } 4 \\
\text { Concorde DVT Edema [104] }\end{array}$ & 2003 & Randomized trial & $\begin{array}{l}\text { Kendall Travel Socks are effective in controlling } \\
\text { edema and reducing DVT incidence in } \\
\text { low- and medium-risk subjects }\end{array}$ \\
\hline $\begin{array}{l}\text { Belcaro et al., } \\
\text { LONFLIT } 5 \text { JAP [70] }\end{array}$ & 2003 & Randomized trial & $\begin{array}{l}\text { Scholl Flights Socks are effective in reducing } \\
\text { DVT incidence in high-risk subjects }\end{array}$ \\
\hline
\end{tabular}

DVT — deep vein thrombosis; LMWH — low-molecular-weight heparin; PE — pulmonary embolism

erroneous because individuals who develop VTEs or DVTs will always have more risk factors for the disease than those who remain disease-free [53]. This selection bias leading to the underrepresentation and, therefore, incorrect conclusions requires attention for future studies [53].

The literature shows a reliance on the $\mathrm{D}$-dimer to determine the presence of DVT. For instance, in the New Zealand Air Traveler's Thrombosis study, only participants with elevated D-dimer scores were included for further investigation [89]. Having a high sensitivity, D-dimer levels are well established, although the false positive rate for other conditions compromises their specificity [94]. Furthermore, a third of the 878 subjects had been administered ASA. Hence, it was suggested that either the patients taking ASA were at highrisk for VTE, or the ASA falsely elevated D-dimers due to gastritis [55]. In another study, 12 subjects were evaluated for asymptomatic thrombosis detected by ultrasound. In 6 of these subjects, no elevation in D-dimer was observed. However, the authors note that the short half-life of D-dimers $(6 \mathrm{~h})$ and the long time (up to $48 \mathrm{~h}$ ) between the 
end of the journey and collecting blood samples could be contributing factors [7]. Schwarz et al. [48] noted 11 out of 27 DVTs, or isolated calf muscle vein thromboses, to have elevated D-dimers. In fact, the high negative predictive value of the D-dimer was reportedly so high that it has been clinically used to exclude DVT in low-risk patients [95]. Even though the role of D-dimers as a VTE marker has been well investigated, its continued role should be revised $[28,55]$.

Although using venography to detect DVTs is considered a gold standard by some researchers, others consider its use unethical in asymptomatic patients. Therefore, alternative methods, such as duplex ultrasonography, have also been used [7]. However, there is a potential to underestimate thromboses due to the specificity, which is reportedly between $79 \%$ and $99 \%$ [7]. Furthermore, duplex ultrasonography sensitivity and specificity decrease for distal DVT when compared to venography [94].

The variability in the time in which the DVT presents (from during the flight to several weeks after) poses a challenge for capturing data outside the normal ranges [53]. Optimal timing of ultrasound scans then should be considered when investigating travel-related VTE. In the BEST study, compressive ultrasonography (CUS) was used in addition to D-dimers to improve detection accuracy. However, most participants declined the CUS after the journey. Only half of the participants who presented elevated D-dimer agreed to a CUS. Additionally, because the scans were performed on arrival, it was not possible to detect developing thrombi. Interestingly, $90 \%$ of subjects with elevated D-dimers reported no VTE symptoms in the follow-up 6 months later [55].

Participant attrition can affect the statistical power of the study. Because the literature largely depends on volunteer recall, many subjects do not continue with subsequent phases of the research. Dropouts due to flight connection problems or other non-medical issues have the potential to affect results, depending on the study design, e.g. in LONFLIT 1 and 2, out of the original 1663 participants, 1577 subjects did not complete the study [59, 92, 96]. Another study by Belcaro et al. [60] showed that only 198 out of 244 individuals completed the study due to logistical problems. Critically, the size of the dropout effect may be difficult to determine. Although it is conceivable that participants will be tired after the journey and dropouts may occur for a multitude of reasons, every possibility to retain subjects should be explored.
Recall bias can be managed with careful study design $[28,53]$. Although difficult to eliminate, recall bias from questionnaires can be decreased with clear guidelines and timely administration of questionnaires [32]. Particular items, such as the exact amount of water/alcohol/fluid intake and the amount of inflight exercise, are available only from the most determined research subjects.

The varying length and duration of flights may need to depend on randomization of data for meaningful statistics [92]. The unpredictable nature of flights and airborne delays or re-routing, which can be difficult to report accurately, may result in inaccuracies in the subsequent analyses.

It is vital then to conduct a series of large international collaborations where uniformity in data collection methodology and consistency in study designs can definitively capture the correct data. To date, the BEST study is an example of such a collaboration, where subjects flew directly from point A to point $\mathrm{B}$, with data collection at both locations eliminating the concern regarding stopovers [6, 92]. In terms of recall biases, the aforementioned largescale studies could even involve airlines through flight attendants, who could remind the participants to record the datapoints at the best junctures.

\section{Pre- or post-surgery considerations}

Endothelial damage can be a proponent for platelet aggregation, causing thrombus formation and increasing the risk of VTE after surgery. It is possible that the danger of VTE is enhanced when surgery and long-haul travel are combined. In fact, the risk of VTE increases nearly 20 times in passengers who had a surgery within a 3-month period [25]. Conversely, in a study involving 1465 total joint arthroplasty patients, 220 traveled by air at a mean of 2.9 days after the surgery and demonstrated no differences between flying and non-flying patients. The study concluded that air travel following total joint arthroplasty is safe [97]. Furthermore, another study also found that preoperative air travel did not influence the risk of VTE after total hip and knee arthroplasty [98].

A case report described a 37-year-old male who traveled from Europe to the USA for elective pelvic surgery. Six days postoperatively, the man died from an acute pulmonary embolism despite having heparin prophylaxis [99]. The authors suggested he had developed a DVT during travel and the symptoms appeared following the surgery. However, the patient did present additional VTE risk factors, including heavy smoking, obesity, and dehydration due to pre-operative preparations [99]. 
Indeed, long-haul travel prior to a major surgery increases the risk of perioperative VTE [99].

\section{COVID-19: Authors' perspectives}

When is it safe to travel long distances by air given a previous COVID-19 infection? The thrombotic risk in COVID-19 is well documented, and in many cases, it is a determinant of disease severity or fatality $[100,101]$. However, to begin answering this question, the issue of the severity with which the individual suffered from the disease should first be evaluated. The introduction of vaccinations brings yet another set of uncertainties to the equation, which adds much complexity to the issue. This question unfortunately cannot be answered scientifically without data and large-scale studies, as described in the previous sections. Given the fluidity of the situation and the amount of new information being learned about the disease every week, the authors are hesitant and reluctant to provide any real opinions.

In any case, exercising the rule of "best judgment" and conservative management, we recommend that those previously infected with COVID-19 wait at least 6 months after resolution of the disease. This includes cases of long COVID-19 where it is not advisable to travel at all until disease-free. Furthermore, flights in these individuals should be limited to less than 6 hours duration. Should the essential need for longer journeys arise, it is advisable to arrange multi-stop journeys with a travel break in between. Lastly, the general methods of VTE prevention as described in this review should be strictly followed:

- Take pharmacological prophylaxis under direction of the individual's physician;

- Choose an aisle seat if possible and/or seat with more legroom;

- Strictly adhere to on-board airline guidance regarding DVT prevention strategies, i.e. calf exercises, periodic foot movements, and frequent ambulation;

- Drink plenty of water and refrain from alcohol, coffee, or other diuretics before, during, and after the flight;

- Purchase and wear recommended compressive flight stockings as directed.

\section{Conclusions}

Great interest in the literature regarding air travel-related VTE reflects global trends. The conditions in which people travel by air over long distances are likely to facilitate VTE formation, most frequently in higher-risk individuals with predisposing factors. As such, preventative measures should be evaluated to decrease the possibility of developing VTE in at-risk individuals. It is likely that as a result of lockdowns and travel restrictions imposed throughout the pandemic, the post-COVID-19 era may well see a sharp rise in air travel as borders reopen. Because long-distance airline travel is mostly international, larger prospective research on an international level should be supported. In particular, studies relating to individuals with post SARS-CoV-2 infection, infection severity, and vaccination effects will be of exceptional value.

\section{Conflict of interest: None declared}

\section{References}

1. International Air Transport Association. 20 Year Passenger Forecast [Internet]. www.iata.org. 2020. https://www.iata.org/en/publications/store/20-year-passenger-forecast/.

2. Bowler T. Carbon fibre planes: Lighter and stronger by design. BBC News [Internet]. 2014 Jan 28. https://www.bbc.com/news/ business-25833264 (cited $2018 \mathrm{Jul} 7$ ).

3. Annual growth in global air traffic passenger demand from 2005 to 2018. Statista [Internet]. 2018 Jun 1. https://www.statista.com/ statistics/193533/growth-of-global-air-traffic-passenger-demand/ (https://www.bbc.com/news/business-25833264).

4. Simpson K. Shelter deaths from pulmonary embolism. Lancet. 1940; 236(6120): 744, doi: 10.1016/s0140-6736(00)92078-6.

5. Homans J. Thrombosis of the deep leg veins due to prolonged sitting. N Engl J Med. 1954; 250(4): 148-149, doi: 10.1056/ NEJM195401282500404, indexed in Pubmed: 13119864.

6. Lapostolle F, Surget V, Borron SW, et al. Severe pulmonary embolism associated with air travel. N Engl J Med. 2001; 345(11): 779-783, doi: 10.1056/NEJMoa010378, indexed in Pubmed: 11556296.

7. Scurr J, Machin S, Bailey-King S, et al. Frequency and prevention of symptomless deep-vein thrombosis in long-haul flights: a randomised trial. The Lancet. 2001; 357(9267): 1485-1489, doi: 10.1016/s0140-6736(00)04645-6.

8. Watson HG. Travel and thrombosis. Blood Rev. 2005; 19(5): 235-241, doi: 10.1016/j.blre.2004.08.001, indexed in Pubmed: 15963832.

9. Sándor T. Travel thrombosis: Pathomechanisms and clinical aspects. Pathophysiology. 2008; 15(4): 243-252, doi: 10.1016/j. pathophys.2008.10.001, indexed in Pubmed: 19019640.

10. Nicolaides AN. Thromboembolism: etiology, advances in prevention, and management. University Park Press, Baltimore 1975: 348.

11. Parsi K, McGrath MA, Lord RSA. Traveller's Venous Thromboembolism: A Review of World Literature, a Survey of World Airlines and an Australian Perspective. Australian New Zealand J Phlebology. 2001; 5(1): 32-53.

12. Schobersberger W, Schobersberger B, Mittermayr M, et al. Air travel, hypobaric hypoxia, and prothrombotic changes. JAMA. 2006; 296(19): 2313-4; author reply 2314, doi: 10.1001/ jama.296.19.2313-b, indexed in Pubmed: 17105791. 
13. Dusse LM, Silva MV, Freitas LG, et al. Economy class syndrome: what is it and who are the individuals at risk? Rev Bras Hematol Hemoter. 2017; 39(4): 349-353, doi: 10.1016/j.bjhh.2017.05.001, indexed in Pubmed: 29150108.

14. Landgraf H, Vanselow B, Schulte-Huermann D, et al. Economy class syndrome: rheology, fluid balance, and lower leg edema during a simulated 12-hour long distance flight. Aviat Space Environ Med. 1994; 65(10 Pt 1): 930-935, indexed in Pubmed: 7832736.

15. Schreijer AJM, Cannegieter SC, Doggen CJM, et al. The effect of flight-related behaviour on the risk of venous thrombosis after air travel. Br J Haematol. 2009; 144(3): 425-429, doi: 10.1111/j.1365-2141.2008.07489.x, indexed in Pubmed: 19036084 .

16. Tao K, Davenport M. Deep venous thromboembolism in a triathlete. J Emerg Med. 2010; 38(3): 351-353, doi: 10.1016/j.jemermed.2008.07.030, indexed in Pubmed: 19128915.

17. Getzin AR, Silberman MR. Iliac artery flow limitations in endurance athletes. Curr Sports Med Rep. 2010; 9(6): 334-337, doi: 10.1249/JSR.0b013e3181fc7250, indexed in Pubmed: 21068564.

18. Béliard S, Feuvrier D, Ducroux E, et al. May Thurner syndrome revealed by left calf venous claudication during running, a case report. BMC Sports Sci Med Rehabil. 2018; 10: 3, doi: 10.1186/ s13102-018-0092-6, indexed in Pubmed: 29435334.

19. Heit JA, Spencer FA, White RH. The epidemiology of venous thromboembolism. J Thromb Thrombolysis. 2016; 41(1): 3-14, doi: 10.1007/s11239-015-1311-6, indexed in Pubmed: 26780736.

20. Lapostolle F, Le Toumelin P, Chassery C, et al. Gender as a risk factor for pulmonary embolism after air travel. Thromb Haemost. 2009; 102(6): 1165-1168, doi: 10.1160/TH09-06-0407, indexed in Pubmed: 19967147.

21. Geerts W, Bergqvist D, Pineo G, et al. Prevention of venous thromboembolism. Chest. 2008; 133(6): 3815-4535, doi: 10.1378/ chest.08-0656.

22. Nopp S, Moik F, Jilma B, et al. Risk of venous thromboembolism in patients with COVID-19: A systematic review and meta-analysis. Res Pract Thromb Haemost. 2020; 4(7): 1178-1191, doi: 10.1002/rth2.12439, indexed in Pubmed: 33043231.

23. Parker S, Mahomed O. Hypoxia and thrombosis in COVID-19: new considerations for air passengers. J Travel Med. 2020; 27(8), doi: 10.1093/jtm/taaa122, indexed in Pubmed: 32710617.

24. Bartholomew JR, Schaffer JL, McCormick GF. Air travel and venous thromboembolism: minimizing the risk. Cleve Clin J Med. 2011; 78(2): 111-120, doi: 10.3949/ccjm.78a.10138, indexed in Pubmed: 21285343.

25. Kuipers S, Venemans A, Middeldorp S, et al. The risk of venous thrombosis after air travel: contribution of clinical risk factors. Br J Haematol. 2014; 165(3): 412-413, doi: 10.1111/bjh.12724, indexed in Pubmed: 24428564.

26. Bauer KA, Lip GY, Leung LLK, et al. Overview of the causes of venous thrombosis. Post TW, ed [Internet]. https://www.uptodate.com/contents/overview-of-the-causes-of-venous-thrombosis/ (cited 2019 Jul 13).

27. Iqbal O, Eklof Bo, Tobu M, et al. Air travel-associated venous thromboembolism. Med Princ Pract. 2003; 12(2): 73-80, doi: 10.1159/000069121, indexed in Pubmed: 12634460.

28. Cannegieter SC, Doggen CJM, van Houwelingen HC, et al. Travel-related venous thrombosis: results from a large populationbased case control study (MEGA study). PLoS Med. 2006; 3(8): e307, doi: 10.1371/journal.pmed.0030307, indexed in Pubmed: 16933962 .
29. Bauer KA, Leung LLK, Mahoney DH, Tirnauer JS. Protein S deficiency. Post TW, ed [Internet]. https:/www.uptodate.com/ contents/protein-s-deficiency/ (cited 2019 Jul 13).

30. Presgrave P, Ma D. Genetic predisposition to venous thromboembolism: molecular basis and a practical guide to management. Australian New Zealand J Phlebology. 2000; 4: 39-45.

31. Bauer KA, Leung LLK, Tirnauer JS. Antithrombin deficiency. Post TW, ed [Internet]. https://www.uptodate.com/contents/ antithrombin-deficiency/.

32. Martinelli I, Taioli E, Battaglioli T, et al. Risk of venous thromboembolism after air travel: interaction with thrombophilia and oral contraceptives. Arch Intern Med. 2003; 163(22): 2771-2774, doi: 10.1001/archinte.163.22.2771, indexed in Pubmed: 14662632.

33. de Groot PG, Lutters B, Derksen RH, et al. Lupus anticoagulants and the risk of a first episode of deep venous thrombosis. J Thromb Haemost. 2005; 3(9): 1993-1997, doi: 10.1111/j.15387836.2005.01485.x, indexed in Pubmed: 16102105.

34. Alemzadeh-Ansari MJ, Kazemisaleh D, Moshkani-Farahani M, et al. Do pregnant women have a higher risk for venous thromboembolism following air travel? Adv Biomed Res. 2015; 4: 60, doi: 10.4103/2277-9175.151879, indexed in Pubmed: 25802829.

35. Heit JA, Kobbervig CE, James AH, et al. Trends in the incidence of venous thromboembolism during pregnancy or postpartum: a 30-year population-based study. Ann Intern Med. 2005; 143(10): 697-706, doi: 10.7326/0003-4819-143-10-20051115000006, indexed in Pubmed: 16287790.

36. Cannegieter SC, Rosendaal FR. Pregnancy and travel-related thromboembolism. Thromb Res. 2013; 131 Suppl 1: S55-S58, doi: 10.1016/S0049-3848(13)70023-9, indexed in Pubmed: 23452744.

37. Brenner B. Interventions to prevent venous thrombosis after air travel, are they necessary? Yes. J Thromb Haemost. 2006; 4(11): 2302-2305, doi: 10.1111/j.1538-7836.2006.02181.x, indexed in Pubmed: 16938123.

38. Reducing the Risk of Venous Thromboembolism during Pregnancy and the Puerperium [Internet]. Royal College of Obstetricians and Gynaecologists; 2015. https://www.rcog.org.uk/globalassets/ documents/guidelines/gtg-37a.pdf (cited 2019 Jul 13).

39. Meroni PL, Moia M, Derksen RH, et al. Venous thromboembolism in the antiphospholipid syndrome: management guidelines for secondary prophylaxis. Lupus. 2003; 12(7): 504-507, doi: 10.1191/0961203303lu389oa, indexed in Pubmed: 12892388.

40. Naouri D, Lapostolle F, Rondet C, et al. Prevention of medical events during air travel: a narrative review. Am J Med. 2016; 129(9): 1000.e1-1000.e6, doi: 10.1016/j.amjmed.2016.05.013, indexed in Pubmed: 27267286.

41. Long haul flight may have led to Jonah Lomu's death. The New Zealand Herald [Internet]. 2015 Nov 23. https://www.nzherald. co.nz/sport/long-haul-flight-may-have-led-to-jonah-lomus-death/ DWWBA7BFLUMHBEHVAYY5SNAECM/ (cited 2020 Dec 9).

42. Abdollahi M, Cushman M, Rosendaal FR. Obesity: risk of venous thrombosis and the interaction with coagulation factor levels and oral contraceptive use. Thromb Haemost. 2003; 89(3): 493-498, indexed in Pubmed: 12624633.

43. Liu F, Silva D, Malone MV, et al. MTHFR A1298C and C677T Polymorphisms Are Associated with Increased Risk of Venous Thromboembolism: A Retrospective Chart Review Study. Acta Haematol. 2017; 138(4): 208-215, doi: 10.1159/000480447, indexed in Pubmed: 29212064.

44. Guba SC, Fink LM, Fonseca V. Hyperhomocysteinemia. An emerging and important risk factor for thromboembolic and car- 
diovascular disease. Am J Clin Pathol. 1996; 106(6): 709-722, doi: 10.1093/ajcp/106.6.709, indexed in Pubmed: 8980346.

45. Botto LD, Yang Q. 5,10-Methylenetetrahydrofolate reductase gene variants and congenital anomalies: a HuGE review. Am J Epidemiol. 2000; 151(9): 862-877, doi: 10.1093/oxfordjournals. aje.a010290, indexed in Pubmed: 10791559.

46. den Heijer M, Koster T, Blom HJ, et al. Hyperhomocysteinemia as a risk factor for deep-vein thrombosis. N Engl J Med. 1996; 334(12): 759-762, doi: 10.1056/NEJM199603213341203, indexed in Pubmed: 8592549.

47. Lievers KJ, Boers GH, Verhoef P, et al. A second common variant in the methylenetetrahydrofolate reductase (MTHFR) gene and its relationship to MTHFR enzyme activity, homocysteine, and cardiovascular disease risk. J Mol Med (Berl). 2001; 79(9): 522-528, doi: 10.1007/s001090100253, indexed in Pubmed: 11692165.

48. Schwarz T, Siegert G, Oettler W, et al. Venous thrombosis after long-haul flights. Arch Intern Med. 2003; 163(22): 2759 -2764, doi: 10.1001/archinte.163.22.2759, indexed in Pubmed: 14662630 .

49. Venous thromboembolic disease and combined oral contraceptives: results of international multicentre case-control study. World Health Organization Collaborative Study of Cardiovascular Disease and Steroid Hormone Contraception. Lancet. 1995; 346(8990): 1575-1582, indexed in Pubmed: 7500748.

50. Contraceptive Use. In: National Survey of Family Growth [Internet]. https://www.cdc.gov/nchs/fastats/contraceptive.htm.

51. Arya R, Barnes JA, Hossain U, et al. Long-haul flights and deep vein thrombosis: a significant risk only when additional factors are also present. Br J Haematol. 2002; 116(3): 653-654, doi: 10.1046/j.0007-1048.2001.03330.x, indexed in Pubmed: 11849227.

52. Pérez-Rodríguez E, Jiménez D, Díaz G, et al. Incidence of air travel-related pulmonary embolism at the Madrid-Barajas airport. Arch Intern Med. 2003; 163(22): 2766-2770, doi: 10.1001/ archinte.163.22.2766, indexed in Pubmed: 14662631.

53. Chandra D, Parisini E, Mozaffarian D. Meta-analysis: travel and risk for venous thromboembolism. Ann Intern Med. 2009; 151(3): 180-190, doi: 10.7326/0003-4819-151-3-20090804000129, indexed in Pubmed: 19581633.

54. Belcaro G, Cesarone MR, Dugall M, et al. Venous Thromboembolism from Air Travel: The LONFLIT Studies. In: Shirato K, editor. Venous Thromboembolism [Internet]. Tokyo: SpringerVerlag; 2005, p. 103-116. http://link.springer.com/10.1007/4-43127121-X_10 (cited 2018 Nov 24).

55. Jacobson BF, Münster M, Smith A, et al. The BEST study: a prospective study to compare business class versus economy class air travel as a cause of thrombosis. S Afr Med J. 2003; 93(7): 522-528, indexed in Pubmed: 12939926.

56. Chee YL, Watson HG. Air travel and thrombosis. Br J Haematol. 2005; 130(5): 671-680, doi: 10.1111/j.1365-2141.2005.05617.x, indexed in Pubmed: 16115122.

57. Domingueti CP, Dusse LM, Carvalho Md, et al. Diabetes mellitus: The linkage between oxidative stress, inflammation, hypercoagulability and vascular complications. J Diabetes Complications. 2016; 30(4): 738-745, doi: 10.1016/j.jdiacomp.2015.12.018, indexed in Pubmed: 26781070.

58. Belcaro G, Stansby G, Nicolaides AN. The Venous Clinic. Imperial College Press, London 1999.

59. Belcaro G, Geroulakos G, Nicolaides AN, et al. Venous thromboembolism from air travel: the LONFLIT study. Angiology. 2001;
52(6): 369-374, doi: 10.1177/000331970105200601, indexed in Pubmed: 11437026.

60. Belcaro G, Cesarone MR, Rohdewald P, et al. Prevention of venous thrombosis and thrombophlebitis in long-haul flights with pycnogenol. Clin Appl Thromb Hemost. 2004; 10(4): 373-377, doi: 10.1177/107602960401000410, indexed in Pubmed: 15497024 .

61. Bartholomew JR, Evans NS. Travel-related venous thromboembolism. Vasc Med. 2019; 24(1): 93-95, doi: 10.1177/1358863X18818323, indexed in Pubmed: 30747601.

62. Pomp ER, Rosendaal FR, Doggen CJM. Smoking increases the risk of venous thrombosis and acts synergistically with oral contraceptive use. Am J Hematol. 2008; 83(2): 97-102, doi: 10.1002/ ajh.21059, indexed in Pubmed: 17726684.

63. Morio H. Pulmonary Thromboembolism Associated with Air Travel in Jaan. In: Shirato K, editor. Venous Thromboembolism. Springer, Tokyo 2005: 87-93.

64. Parsi K. Traveller's Venous Thromboembolism [Master of Science (Medicine)]. University of New South Wales, Sydney 2001.

65. White R, Keenan C. Effects of race and ethnicity on the incidence of venous thromboembolism. Thromb Res. 2009; 123: S11-S17, doi: 10.1016/s0049-3848(09)70136-7.

66. Keenan CR, White RH. The effects of race/ethnicity and sex on the risk of venous thromboembolism. Curr Opin Pulm Med. 2007; 13(5): 377-383, doi: 10.1097/MCP.0b013e3281eb8ef0, indexed in Pubmed: 17940480.

67. Inflight wellbeing. Air New Zealand [Internet]. https://www. airnewzealand.co.nz/inflight-wellbeing (cited 2018 Aug 7).

68. Hitos K, Cannon M, Cannon S, et al. Effect of leg exercises on popliteal venous blood flow during prolonged immobility of seated subjects: implications for prevention of travel-related deep vein thrombosis. J Thromb Haemost. 2007; 5(9): 1890-1895, doi: 10.1111/j.1538-7836.2007.02664.x, indexed in Pubmed: 17723128.

69. Chen AH, Frangos SG, Kilaru S, et al. Intermittent pneumatic compression devices -- physiological mechanisms of action. Eur J Vasc Endovasc Surg. 2001; 21(5): 383-392, doi: 10.1053/ ejvs.2001.1348, indexed in Pubmed: 11352511.

70. Belcaro G, Cesarone MR, Nicolaides AN, et al. Prevention of venous thrombosis with elastic stockings during long-haul flights: the LONFLIT 5 JAP study. Clin Appl Thromb Hemost. 2003; 9(3): 197-201, doi: $10.1177 / 107602960300900303$, indexed in Pubmed: 14507107.

71. Cesarone MR, Belcaro G, Nicolaides AN, et al. The LONFLIT4-Concorde - Sigvaris Traveno Stockings in Long Flights (EcoTraS) Study: a randomized trial. Angiology. 2003; 54(1): 1-9, doi: 10.1177/000331970305400101, indexed in Pubmed: 12593490.

72. Sajid MS, Tai NRM, Goli G, et al. Knee versus thigh length graduated compression stockings for prevention of deep venous thrombosis: a systematic review. Eur J Vasc Endovasc Surg. 2006; 32(6): 730-736, doi: 10.1016/j.ejvs.2006.06.021, indexed in Pubmed: 16931066.

73. Cesarone MR, Belcaro G, Nicolaides AN, et al. Prevention of venous thrombosis in long-haul flights with Flite Tabs: the LONFLIT-FLITE randomized, controlled trial. Angiology. 2003; 54(5): 531-539, doi: 10.1177/000331970305400502, indexed in Pubmed: 14565628.

74. Lurie F, Kistner RL, Eklof Bo, et al. Prevention of air travelrelated deep venous thrombosis with mechanical devices: active foot movements produce similar hemodynamic effects. J Vasc Surg. 2006; 44(4): 889-891, doi: 10.1016/j.jvs.2006.06.019, indexed in Pubmed: 17012016. 
75. Comerota AJ, Katz ML, White JV. Why does prophylaxis with external pneumatic compression for deep vein thrombosis fail? Am J Surg. 1992; 164(3): 265-268, doi: 10.1016/s00029610(05)81083-9, indexed in Pubmed: 1415927.

76. Abramowitz HB, Gertz SD. Venous stasis, deep venous thrombosis and airline flight: can the seat be fixed? Ann Vasc Surg. 2007; 21(3): 267-271, doi: 10.1016/j.avsg.2007.03.007, indexed in Pubmed: 17484958.

77. Coleridge PD. Independent Clinical Trials. https://airogym.com/ en/content/17-independent-clinical-trials (cited 2018 Nov 24).

78. Paydar S, Sabetian G, Khalili H, et al. Management of Deep Vein Thrombosis (DVT) Prophylaxis in Trauma Patients. Bull Emerg Trauma. 2016; 4(1): 1-7, indexed in Pubmed: 27162921.

79. Pai M, Douketis JD. Prevention of venous thromboembolism in adult travelers. Post TW, ed [Internet]. https://www.uptodate. com/contents/prevention-of-venous-thromboembolism-in-adulttravelers (cited 2019 Jul 7).

80. Bevis P, Smith F. Deep vein thrombosis. Surgery (Oxford). 2016; 34(4): 159-164, doi: 10.1016/j.mpsur.2016.02.001.

81. Cesarone MR, Belcaro G, Nicolaides AN, et al. Venous thrombosis from air travel: the LONFLIT3 study — prevention with aspirin vs low-molecular-weight heparin (LMWH) in high-risk subjects: a randomized trial. Angiology. 2002; 53(1): 1-6, doi: 10.1177/000331970205300101, indexed in Pubmed: 11863301.

82. Martel N, Lee J, Wells PS. Risk for heparin-induced thrombocytopenia with unfractionated and low-molecular-weight heparin thromboprophylaxis: a meta-analysis. Blood. 2005; 106(8): 2710-2715, doi: 10.1182/blood-2005-04-1546, indexed in Pubmed: 15985543.

83. Chamnanchanunt S, Rojnuckarin P. Direct Oral Anticoagulants and Travel-related Venous Thromboembolism. Open Med (Wars). 2018; 13: 575-582, doi: 10.1515/med-2018-0085, indexed in Pubmed: 30519635.

84. Weitz JI, Bauersachs R, Beyer-Westendorf J, et al. EINSTEIN CHOICE Investigators. Two doses of rivaroxaban versus aspirin for prevention of recurrent venous thromboembolism. Rationale for and design of the EINSTEIN CHOICE study. Thromb Haemost. 2015; 114(3): 645-650, doi: 10.1160/TH15-02-0131, indexed in Pubmed: 25994838.

85. Clark SL, Onida S, Davies A. Long-haul travel and venous thrombosis: What is the evidence? Phlebology. 2018; 33(5): 295-297, doi: 10.1177/0268355517717423, indexed in Pubmed: 28650273.

86. Zhu Q, Zhou S, Liu Z. Fondaparinux and Direct Oral Anticoagulants. J Am Coll Cardiol. 2018; 71(15): 1710, doi: 10.1016/j. jacc.2017.12.067.

87. National Clinical Guideline Centre (UK). Venous Thromboembolic Diseases: The Management of Venous Thromboembolic Diseases and the Role of Thrombophilia Testing [Internet]. London: Royal College of Physicians (UK); 2012. (National Institute for Health and Clinical Excellence: Guidance). http://www.ncbi. nlm.nih.gov/books/NBK132796/ (cited 2018 Jul 9).

88. Wolowacz SE, Roskell NS, Plumb JM, et al. Efficacy and safety of dabigatran etexilate for the prevention of venous thromboembolism following total hip or knee arthroplasty. A meta-analysis. Thromb Haemost. 2009; 101(1): 77-85, indexed in Pubmed: 19132192.

89. Hughes RJ, Hopkins RJ, Hill S, et al. Frequency of venous thromboembolism in low to moderate risk long distance air travellers: the New Zealand Air Traveller's Thrombosis (NZATT) study. Lancet. 2003; 362(9401): 2039-2044, doi: 10.1016/s01406736(03)15097-0.

90. Ferrari E, Chevallier T, Chapelier A, et al. Travel as a risk factor for venous thromboembolic disease: a case-control study. Chest.
1999; 115(2): 440-444, doi: 10.1378/chest.115.2.440, indexed in Pubmed: 10027445.

91. Kraaijenhagen R, Haverkamp D, Koopman M, et al. Travel and risk of venous thrombosis. Lancet. 2000; 356(9240): 1492-1493, doi: 10.1016/s0140-6736(00)02878-6.

92. Aryal KR, Al-Khaffaf H. Venous thromboembolic complications following air travel: what's the quantitative risk? A literature review. Eur J Vasc Endovasc Surg. 2006; 31(2): 187-199, doi: 10.1016/j.ejvs.2005.08.025, indexed in Pubmed: 16230037.

93. Stroup DF. Meta-analysis of Observational Studies in Epidemiology. A Proposal for Reporting. JAMA. 2000; 283(15): 2008.

94. Tovey C, Wyatt S. Diagnosis, investigation, and management of deep vein thrombosis. BMJ. 2003; 326(7400): 1180-1184, doi: 10.1136/bmj.326.7400.1180, indexed in Pubmed: 12775619.

95. Wells PS, Anderson DR, Rodger M, et al. Evaluation of D-dimer in the diagnosis of suspected deep-vein thrombosis. N Engl J Med. 2003; 349(13): 1227-1235, doi: 10.1056/NEJMoa023153, indexed in Pubmed: 14507948.

96. Bell ML, Kenward MG, Fairclough DL, et al. Differential dropout and bias in randomised controlled trials: when it matters and when it may not. BMJ. 2013; 346: e8668, doi: 10.1136/bmj.e8668, indexed in Pubmed: 23338004.

97. Cooper HJ, Sanders SA, Berger RA. Risk of symptomatic venous thromboembolism associated with flying in the early postoperative period following elective total hip and knee arthroplasty. J Arthroplasty. 2014; 29(6): 1119-1122, doi: 10.1016/j. arth.2014.01.005, indexed in Pubmed: 24556112.

98. Citak M, Klatte TO, Suero EM, et al. Are patients with preoperative air travel at higher risk for venous thromboembolism following primary total hip and knee arthroplasty? Technol Health Care. 2015; 23(3): 307-311, doi: 10.3233/THC-150893, indexed in Pubmed: 25669208.

99. Gajic O, Sprung J, Hall BA, et al. Fatal acute pulmonary embolism in a patient with pelvic lipomatosis after surgery performed after transatlantic airplane travel. Anesth Analg. 2004; 99(4): 1032-1034, doi: 10.1213/01.ANE.0000131725.40714.9F, indexed in Pubmed: 15385344.

100. Han H, Yang L, Liu R, et al. Prominent changes in blood coagulation of patients with SARS-CoV-2 infection. Clin Chem Lab Med. 2020; 58(7): 1116-1120, doi: 10.1515/cclm-2020-0188, indexed in Pubmed: 32172226 .

101. Helms J, Tacquard C, Severac F, et al. CRICS TRIGGERSEP Group (Clinical Research in Intensive Care and Sepsis Trial Group for Global Evaluation and Research in Sepsis). High risk of thrombosis in patients with severe SARS-CoV-2 infection: a multicenter prospective cohort study. Intensive Care Med. 2020; 46(6): 1089-1098, doi: 10.1007/s00134-020-06062-x, indexed in Pubmed: 32367170.

102. Schwarz T, Langenberg K, Oettler W, et al. Deep vein and isolated calf muscle vein thrombosis following long-haul flights: pilot study. Blood Coagul Fibrinolysis. 2002; 13(8): 755-757, doi: 10.1097/00001721-200212000-00013, indexed in Pubmed: 12441916.

103. Belcaro G, Cesarone MR, Shah SSG, et al. Prevention of edema, flight microangiopathy and venous thrombosis in long flights with elastic stockings. A randomized trial: The LONFLIT 4 Concorde Edema-SSL Study. Angiology. 2002; 53(6): 635-645, doi: 10.1177/000331970205300603, indexed in Pubmed: 12463616.

104. Cesarone MR, Belcaro G, Errichi BM, et al. The LONFLIT4-Concorde Deep Venous Thrombosis and Edema Study: prevention with travel stockings. Angiology. 2003; 54(2): 143-154, doi: 10.1177/000331970305400202, indexed in Pubmed: 12678188. 